\title{
True Potato Seed: Changing Potato Propagation from Vegetative to Sexual
}

\author{
Noel Pallais \\ International Potato Center, Apartado 5969, Lima, Peru
}

\begin{abstract}
"This thing called TPS [true potato seed] is a part of the future; how close that future is to us depends on whether people like us have what it takes."

\section{R. Sawyer, 1984}

The potato has traditionally been propagated vegetatively, but this may change someday. Today, many of the tubers produced from true potato seed (TPS), i.e., sexual seed, of selected potato progenies at the International Potato Center [Centro Internacional de la Papa (CIP)] could be sold in the markets of developing countries (Mendoza, 1984). Over the past decade of research at CIP, TPS technology has advanced significantly. More than 40 National Potato Programs are currently investigating the use of TPS. In eight countries, potatoes are being produced commercially from the first generation of tubers grown from TPS (Malagamba, 1988).

CIP's more widely tested TPS progenies are crosses between two tetraploid clones selected for progeny uniformity of tuber characteristics. Further improvements in TPS progeny uniformity could be obtained by using pollen selection techniques (Pallais et al., 1985a) and sorting for specific seed size characteristics. High levels of hybrid vigor and uniformity of tuber yields may be transmitted to the TPS progeny when produced with $2 \mathrm{n}$ pollen (first division restitution) of selected diploid clones crossed onto flowers of tetraploid mother plants (Peloquin, 1982; Peloquin et al., 1984). Ovules with unreduced gametes can also be formed in some potato diploids (Mendiburu and Peloquin, 1977). TPS may possibly be produced by crossing two diploid parents, which form $2 n$ gametes, which would maximize heritability, heterozygosity, and, presumably, yield and uniformity.

At present, the TPS technology has the possibility of being adopted in many tropical regions because high-quality seed tubers are difficult to produce in warm climates (Malagamba, 1988) because of the high inoculum pressure of the many tuber-borne pathogens

Received for publication 15 Aug. 1989. The cost of publishing this paper was defrayed in part by the payment of page charges. Under postal regulations, this paper therefore must be hereby marked advertisement solely to indicate this fact. ${ }^{1}$ Plant Physiologist. that cause seed tuber quality to deteriorate rapidly. Viruses are among the most important endemic tropical pathogens of potato crop when vegetatively propagated, and can be responsible for decreasing yields severely. This is one of the principal causes for the low consumption of potatoes in many developing countries. Fortunately, virus-free TPS can be produced through sexual reproduction, even though the mother plant may be virus-infested. This is one reason for using seed tubers produced from TPS rather than clonal seed tubers for potato propagation in warm climate areas.

\section{Current TPS use}

The most commonly employed methods of using TPS are:

1) True seed is sown in favorable and protected environments and the seedlings are then transplanted to the field for producing table potatoes (Malagamba, 1983, 1984). This method is favored by scientists who are involved in evaluating tuber-yield potential among various TPS populations. After 5 years of experience in Asia with TPS technology on farmers' fields, however, Vander Zaag et al. (1989) concluded that "transplanting is not a feasible practice for table potato production with existing progenies."

2) Small tubers (2 to $5 \mathrm{~cm}$-seedling tubers) are harvested from TPS seedlings transplanted to the field at high density (Wiersema, 1986). These tubers are stored and then planted in the subsequent growing season.

3) Smaller seedling tubers ( $<3 \mathrm{~cm}-$ minitubers) are produced by sowing TPS in specially prepared seed beds under nursery conditions and are protected with screens from virus vectors and other pathogens (Wiersema and Cabello, 1986). High multiplication rates can be obtained under favorable conditions, with $<1 \mathrm{~g}$ of TPS sown in a $1-\mathrm{m}^{2}$ seed bed, $\approx 10 \mathrm{~kg}$ of virus-free minitubers can be produced, enough to plant $100 \mathrm{~m}^{2}$ of potatoes. The production of minitubers provides $\mathrm{Na}$ tional Potato Programs in many developing countries with a viable alternative to the traditional seed tuber systems.

Methods 2 and 3 for using TPS are currently considered to be the most feasible for adoption by farmers in tropical areas. The possibility of producing virus-free seed tubers in virus-laden environments is an impor- tant advantage of TPS. In China, $\approx 20,000$ ha of potatoes are produced using seedling tubers (Song, 1984). In Egypt, a large-scale minituber seed production system has been started (R. El-Bedewi, personal communication).

Of the three methods outlined above, however, only TPS seedlings for transplanting can be described as true sexual propagation in the potato. In the other two methods, TPS is used to produce seed tubers for vegetative propagation. Using TPS for directseeding a crop of potatoes in the field has been tried (Ghate et al., 1983) without much success (Phatak et al., 1988), and is not considered a feasible alternative. Nonetheless, if possible, direct sowing of TPS may be the most reasonable method for propagating the potato sexually. To grow 1 ha of potatoes by this method, $<100 \mathrm{~g}$ of TPS would be needed. The cost of this seed averages less than U.S. $\$ 100$, while the price of $2 \mathrm{t}$ of highquality clonal seed tubers in many developing countries can exceed U.S.\$1000.

\section{Producing high-quality TPS}

Research on TPS technology started at CIP in 1977. The factors known to be involved in the production of high-quality seed in other small-seeded crops (Delouche, 1980) have only recently begun to receive research attention in TPS. Recent field trials at CIP have demonstrated that the contention that TPS cannot be used for producing potatoes directly was premature. In the past, research on TPS technology in farmers' fields was mostly conducted using viable seed, but without any regard to seed dormancy and vigor. Low-quality TPS usually does not germinate uniformly and produces slowgrowing seedlings vulnerable to transplanting shock. Thus, plant maturity is extended and production of large tubers is delayed or small tubers must be harvested due to the usually short growing seasons in tropical areas. When high-quality and nondormant TPS is sown, the seedlings can be uniformly ready for transplanting after only 3 weeks, instead of the 6 weeks that are usually necessary with low-quality or dormant seed. In a field experiment during Summer 1989 in Lima, Peru (unpublished data), seedlings from nondormant seed, unlike those from dormant ones, were shown to be able to better with- 
stand bare-root transplanting shock and grow vigorously soon after transplanting and to a size similar to those of plants grown from seed tubers.

Among the various techniques found to be effective for producing vigorous or highquality TPS are: 1) Producing TPS in mother plants grown from pathogen-tested seed tubers under favorable long-day, cool, dry environments (Pallais et al., 1984); 2) applying more $\mathrm{N}$ than needed for tuber production, and applying $\mathrm{N}$ continuously during seed development to delay mother-plant senescence and to extend berry maturation periods (Pallais et al., 1987a); 3) harvesting the, potato berries at their optimum stage of on-plant seed maturity (Pallais et al., 1989); 4) proper seed extraction, surface disinfection, drying, and storing (Pallais et al., 1984; Pallais and Fong, 1989); and 5) seed priming instead of the standard gibberellic acid (GA) presowing treatment (Pallais, 1989).

The need for high-quality (early vigor) seed must be properly understood. The concept of sexual seed quality is not necessarily related to final yields (Barrington, 1971), as it might be in the case of seed tuber quality. The production of high-quality TPS may require favorable growing conditions, such as long days and cool, dry climates (Delouche, 1980; Pallais et al., 1984, 1985b). Nevertheless, sufficient quantities of viable TPS can be produced in the short-day environments of the humid and cooler climates of the highland tropics (Malagamba, 1988). Large quantities of open-pollinated (OP) berries may be easily harvested from potato clones growing in farmers' fields in many such regions (Hoang et al., 1988). Given time, this OP seed will produce high yields of seedling tubers in some genotypes because the conditions during seedling emergence are optimized for this purpose. TPS produced by virus-infected mother plants may eventually germinate and be able to produce high-yielding virus-free seedling tubers. However, a diseased mother plant is not a likely candidate for producing TPS with optimum sowing potential. A small seed must be more than just virus-free for effective production in unfavorable environments. The necessity for high quality in small sexual seeds is specifically related to the conditions during emergence and seedling performance, i.e., the establishment phase of a field stand under unfavorable conditions. Seed of high quality is a requirement during the crucial and most vulnerable first step of plant growth and development for eventual successful crop production. However, high-quality seed may also be important to increase the possibilities for adoption of this new technology. In Vietnam, for, example, only $50 \%$ of the farmers who were given OP TPS collected from farmers' fields were successful (Hoang et al., 1988).

\section{TPS dormancy}

One special seed characteristic of sexually propagated crops-seed dormancy-needs to be considered in the use of vigorous TPS.
Increased seed vigor of mature seed produced with high $\mathrm{N}$ may be accompanied by greater seed dormancy (Pallais and Fong, 1989; Pallais et al., 1989). These dormant seeds would need to be stored for long periods before they could be sown effectively. Cool and dry storage conditions lengthen the postharvest storage requirement for decreasing dormancy of TPS (Simmonds, 1968). However, low seed moisture is needed to preserve seed vigor (Pallais and Fong, 1989). In the past, TPS dormancy was not considered to be an important problem because gibberellic acid (GA) could be used to promote germination in newly harvested seed (Accatino and Malagamba, 1982; Spicer, 1961). Studies still are being conducted on better techniques for applying GA to break TPS dormancy (Bamberg and Hanneman, 1984; M. Upadhya, personal communication). However, dormant TPS that are induced to emerge by GA begin growth as etiolated plants, and produce significantly less dry matter in the foliage during the first 17 days after sowing than do nondormant ( $\geq 6$ months of storage) seeds (Pallais, 1989). In fact, a sufficient period (6 to 12 months) of seed after-ripening in storage is necessary before TPS priming can be effective (Pallais et al., 1990). More recently, Pallais et al. (1991) found that a crucial step in high-quality TPS production, when intended for sowing under high temperature (>25 C), is storage of seed dry ( $5 \%$ to $7 \%$ moisture) at $\approx 20 \mathrm{C}$ for $\approx 18$ months before sowing.

Seed. dormancy probably served the survival of potato species by increasing the chances of germination under conditions more favorable to plant growth and development in nature (Taylorson, 1982; Witcombe and Whittington, 1972). Nevertheless, seed dormancy is a nuisance for crop production and considerably lowers the possibilities of using the true seed for producing potatoes directly (Pallais, 1987). Before the full potential of TPS for sowing a crop of potatoes can be fairly evaluated, the vegetatively propagated potato must be redomesticated for sexual propagation by sufficiently reducing dormancy in the TPS progeny through breeding and selection. Evidence in some wild species suggests that seed dormancy may be selected out of a population in as few as three generations (Thompson, 1981; Witcombe and Whittington, 1972). However, tuber dormancy, usually a desirable characteristic in potatoes, has been positively associated with TPS dormancy (Simmonds, 1964). Therefore, the selection of TPS progenies with little or no seed dormancy and which are capable of producing dormant tubers appears difficult. Nevertheless, the evidence provided by Simmonds (1964) indicates that correlation of tuber and TPS dormancy is not invariably present.

\section{Redomestication of the potato}

Domesticating TPS may be thought of as genetic enhancement of seed quality or early sowing characteristics. The recently developed physiological techniques for producing high-quality TPS maybe used to help breeders focus on the genotype, which is really the most important factor in producing more vigorous TPS progenies. The TPS characteristics of slow emergence and low seedling vigor, particularly evident when newly harvested seed is sown, need to be seriously addressed in potato research. The potato is challenging plant scientists to redomesticate this species for sexual propagation. Clearly, the TPS characteristics of emergence and early seedling performance under unfavorable field conditions (e.g., supra-optimal temperature) should be included in the selection process for superior TPS progenies. The first step for undertaking this challenge could be to study the inheritance of TPS dormancy characteristics using those genotypes that have already demonstrated a high yield potential.

Recent evidence has shed some light on the feasibility of the proposed genetic enhancement of the emergence characteristics of TPS. Evaluations of $\approx 800$ accessions from the extensive collection of potato germplasm (6550 accessions) available at CIP (Huaman, 1987) have indicated that variability does exist for low seed dormancy and terminability at high temperature (Pallais et al., 1987b). Also, one of the 10 most promising TPS hybrids selected at CIP, when tested soon after harvest ( 3 to 6 months), was found to be 2 to 6 times more vigorous during early seedling growth than the others (Pallais et al., 1990). This less-dormant TPS cross (A1) involves the cultivar Atlantic used as a mother plant and the clone LT-7 as the pollen source. The latter is a clone selected as a TPS "male" parent for its superior adaptation to lowland tropical conditions (International Potato Center, 1988). The A1 progeny produces stable and acceptable potato yields of dormant tubers that are reasonably uniform and attractive in shape (H. Mendoza, personal communication). A superior genetic potential for emergence at supra-optimal temperature (34C) was also discovered in TPS of A1 stored for $\geq 7$ months (Pallais et al., 1991).

I propose that high-quality seed of cross A1 should become the first control genotype used in the selection process for superior early seedling characteristics in TPS progenies. Indeed, the seedling emergence performance of A1 seed comes close enough to that of sexually propagated tomatoes to permit a purposeful search for crosses that permit early seedling establishment for TPS under field conditions.

The discussion on potato redomestication should profit from the participation of horticultural scientists who are familiar with sexual propagation in problematic smallseeded crops. For this reason, I have chosen HortScience as the forum to express my viewpoint and hope that it will elicit comments or suggestions. Most crop seed physiologists must consider the vigor in domesticated species and strive for agronomically important improvements in seed quality. Much more of this type of work is still required for TPS. However, the case for sexually propagating potatoes allows and requires an important genetic modification of 
the existing undesirable seedling growth characteristics in TPS progenies. I call this needed genetic improvement a redomestication process because selecting out the wild seed dormancy characteristic is akin to taming TPS for human use.

I suggest that selection of superior TPS crosses with improved early sowing (seedling emergence) and final-planting (tuber yields) value may be accomplished rapidly by testing advanced progenies for low dormancy and high seed vigor characteristics. The rate of emergence and the percentage of emergence from soil 10 days after sowing and seedling dry weight at 17 days under high temperature (mean $>25 \mathrm{C}$ ) are the basic set of criteria that may be used for evaluation. The results (cross A1) of seed vigor testing among the selected TPS crosses demonstrate the potential worth of this strategy (Pallais et al., 1991). A longer-term strategy was suggested by our numerous observations on the seedling performance of high-tuberyielding TPS progenies that have low early sowing value because of their more intense seed dormancy. For example, the cross of the cultivar Serrana $\times$ LT-7 consistently produces some seed (10\% to $20 \%$ ) able to germinate rapidly at high temperatures soon after harvest. Many of these seedlings also grow vigorously; breeding and selection using some of these genotypes may prove to be desirable for developing the superior TPS parental materials of the future.

The characteristics of the seed during emergence must be studied closely if sexual propagation of potatoes is ever going to be seriously tested. The possibilities of TPS technology to increase potato production and consumption in marginal potato production areas deserve to be thoroughly examined.

\section{Literature Cited}

Accatino, P. and P. Malagamba. 1982. Potato production from true seed. Centro International de la Papa, Lima, Peru.

Bamberg, J.B. and R.E. Hanneman, Jr. 1984. Hastened germination of slow germinating potato seed lots by the use of gibberellic acid and activated charcoal. Amer. Potato J. 61:517-518.

Delouche, J.C. 1980. Environmental effects on seed development and seed quality. HortScience 15:775-779.

Ghate, S.R., C.A. Jaworski, and S.C. Phatak. 1983. Emergence and plant stand of pre-germinated true potato seed in warm climates. Amer. Potato J. 60:557-562.

Barrington, J.F. 1971. The necessity for high- quality vegetable seed. HortScience 6:550-551. Hoang, V.T., P.X. Liem, V.B. Dan, N.D. Dam, N.X. Linh, N.V. Viet, P.X. Tung, and P. Vander Zaag. 1988. True potato seed research and development in Vietnam. Amer. Potato J. 65:295-300.

Huaman, Z. 1987. Status of the native Andean cultivated potato collection maintained at CIP. Planning Conf., Strategies for the Conservation of Potato Genetic Resources. International Potato center, Lima, Peru. p. 27-44.

International Potato center (CIP). 1988. Annual report CIP 1988. p. 147-163.

Malagamba, P. 1983. Reducing the effect of stress during the establishment and growth of potatoes from true seed in hot climates, p. 127-128. In: W.L. Hooker (cd.). Research for the potato in the year 2000. International Potato Center, Lima, Peru.

Malagamba, P. 1984. Agronomic management for transplanting TPS seedlings. Innovative methods for propagating potatoes. Rpt. 28th Planning Conf., International Potato Center, Lima, Peru. p. 63-93.

Malagamba, P. 1988. Potato production from true seed in tropical climates. HortScience 23:495500

Mendiburu, A.O. and S.J. Peloquin. 1977. Bilateral sexual polyploidization in potatoes. Euphytica 26:573-583.

Mendoza, H. 1984. Selection of uniform progenies to use in TPS commercial potato production. Innovative methods for propagating potatoes. Rpt. 28th Planning Conf., International Potato Center, Lima, Peru. p. 5-16.

Pallais, N. 1987. True potato seed quality. Theor. Applied Genet. 73:784-792.

Pallais, N. 1989. Osmotic priming true potato seed: Effects of seed age. Potato Res. 32:235-244.

Pallais, N. and N. Fong. 1989. A compromise strategy for storing high-quality true potato seed. Abstr. 74th Annu. Mtg. Amer. Potato J. 66:538.

Pallais, N., H. Asmat, N. Fong, and R. Garcia. 1989. Factors affecting seedling vigor in potatoes: I. Stage of seed maturity. Amer. Potato J. 66:793-801.

Pallais, N., N. Fong, and D. Berrios. 1984. Research on the physiology of potato sexual seed production. Innovative methods for propagating potatoes. Rpt. 28th Planning Conf., International Potato Center, Lima, Peru. p. 149-168.

Pallais, N., P. Malagamba, N. Fong, R. Garcia, and P. Schmiediche. 1985a. Pollen selection through storage: A tool for improving true potato seed quality?, p. 153-158. In: D.L. Mulcahy, G.B. Mulcahy, and E. Ottaviano (eds.). Biotechnology and ecology of pollen. SpringerVerlag, New York.

Pallais, N., J. Kalazich, and J.S. Rojas. 1985b. Physical relationships between berries and seeds of potato. HortScience 21: 1359-1360.

Pallais, N., S. Villagarcia, N. Fong, J. Tapia, and R. Garcia. 1987a. Effect of supplemental nitro- gen on true potato seed weight. Amer. Potato J. 64:483-491.

Pallais, N., Z. Huaman, and S. Hopmans. 1987b. Screening true potato seed of native Andean cultivars for terminability under high temperatures. Eur. Assn. Potato Res., 10th Triennial Conf. Aalborg, Denmark. p. 292-293.

Pallais, N., N. Fong, R. Falcon, and R. Garcia. 1990. Factors affecting seedling vigor in potatoes: H. Genotype, after-ripening, and pre-sowing treatments. Amer. Potato J. 67:109-119.

Pallais, N., N.Y. Espinola, R.M. Falcon, and R.S. Garcia. 1991. Improving seedling vigor in sexual seeds of potato under high temperature. HortScience 26:296-299.

Peloquin, S.J. 1982. Meiotic mutants in potato breeding. Stadler Symp. Univ. Missouri, Columbia. 14:1-11.

Peloquin, S. J., C.G. Arndt, and H.M. KinadeMariam. 1984. Utilization of ploidy manipulations in breeding for TPS. Innovative methods for propagating potatoes. Rpt. 28th Planning Conf., International Potato Center, Lima, Peru. p. 17-23.

Phatak, S. C., S.R. Ghate, C.J. Jaworsky, and R.D. Gataitis. 1988. Needed engineering aids and mechanization for true potato seed seedling, seedling tuber harvest, and seedling tuber planting. HortScience 23:504-505.

Simmonds, N.W. 1964. The genetics of seed and tuber dormancy in cultivated potatoes. Heredity 19:489-504.

Simmonds, N.W. 1968. Prolonged storage of potato seeds. Eur. Potato J. 11:150-156.

Song, B.F. 1984. Use of potato seed in China. CIP Circ. 12:6.

Spicer, P.B. 1961. Use of gibberellin to hasten germination on Solarium seed. Nature (London) 189:327-328.

Taylorson, R.B. 1982. Interaction of phytochrome and other factors in seed germination, p. 323-346. In: A.A. Khan (cd.). The physiology and biochemistry of seed development, dormancy and germination. Elsevier, New York.

Thompson, P.A. 1981. Ecological aspects of seed germination, p. 9-42. In: J.R. Thompson (cd.). Adv. Res. Technol. Seeds, Part 6. Intl. Seed Test. Assn., Wageningen, Netherlands.

Vander Zaag, P., B. Susana, Z. Ganga, and S. Gayao. 1989. Field evaluation of the true potato seed in the Philippines. Amer. Potato J. 66:109117.

Wiersema, S.G. 1986. A method of producing seed tubers from true potato seed. Potato Res. 29:225-237.

Wiersema, S.G. and R. Cabello. 1986. Comparative performance of different-sized tubers derived from true seed. Amer. Potato J. 63:241249.

Witcombe, J.R. and W.J. Whittington. 1972. The effects of selection for reduced dormancy in charlock (Sinapsis arvensis). Heredity 29:3749. 